\title{
Husbands' Knowledge of Obstetric Danger Signs, and Level of Birth Preparedness and Complication Readiness and Associated Factors in Wara Jarso, North Shewa, Oromia, Ethiopia, 2019
}

\author{
Girma Teferi Mengistu $^{1^{*}}$ Sena Balina Kitila ${ }^{2} \quad$ Mesfin Beharu Deme ${ }^{3}$ \\ 1.Wolkite University, College of Medicine and Health Science, Department of Nursing \\ 2.Jimma University, Institute of Health, Faculty of Health Science, School of Nursing and Midwifery \\ 3.Jimma University, Institute of Health, Faculty of Health Science, School of Nursing and Midwifery, IPD \\ Coordinator of JUMC Medical - Surgical Case Team
}

\begin{abstract}
Background: Most women have uneventful pregnancies and childbirth. Birth preparedness and complication readiness prevents these problems. Globally, 830 women die every day from preventable causes related to pregnancy and childbirth. Ethiopia is one of developing country with 412 maternal mortality rate. However different intervention was made still mothers preparation for birth is low while the husbands are decision makers and control resources. The aim of the study was to assess husbands' knowledge of obstetric danger signs, level of birth preparedness and complication readiness and associated factors in Wara Jarso, Ethiopia.

Methods: Community based cross sectional study was conducted in Wara Jarso from April 8 to 28 2019. The study participants were interviewed using simple random sampling and data were coded, cleaned and entered to Epidata version 3.1, exported to SPSS 23. Bivariate and multivariable logistic regression was used to identify association of independent variables with husbands' level of birth preparedness and complication readiness at $\mathrm{p}<0.05,95 \% \mathrm{CI}$. The results were presented using descriptive, tables and diagrams.

Result: The data were collected from 593 participants, and 574 were completed the interview giving the response rate of $96.8 \%$. The mean age of respondents was $36.5 \pm 7.8$ years. Knowledge of obstetric danger signs of the respondents was $32.06 \%$ while level of birth preparedness and complication readiness was $22.30 \%$. Merchant husbands ( $\mathrm{AOR}=2.272(95 \% \mathrm{CI} 1.153,4.478), \mathrm{p}=.018)$, living in urban $(\mathrm{AOR}=5.550(95 \% \mathrm{CI} 2.211$, 13.933), $\mathrm{p}=.001$ ) escorting their wives to health institution ( $\mathrm{AOR}=2.217(95 \% \mathrm{CI} 1.095,4.487), \mathrm{p}=.027$ ) accept buying material and clothes for baby before delivery (AOR $=3.599(95 \% \mathrm{CI} 1.995,6.490), \mathrm{p}=.001)$ and knowledgeable about obstetric danger sign $(\mathrm{AOR}=4.957(95 \% \mathrm{CI} 2.726,9.016), \mathrm{p}=.001)$ were variables associated with husbands' birth preparedness and complication readiness.

Conclusion and recommendation: The husbands' knowledge of obstetric dangers signs and their level of preparation was low. Occupation, residence, escort wife, accepting buying materials and knowledge were variables associated with preparation. Therefore, district health office, policy makers, planners, and HEW have to work on awareness creation about obstetric danger signs and how to increase level of preparation among husbands.
\end{abstract}

Keywords: Knowledge of Danger Signs, Birth Preparedness, Complication Readiness, Wara Jarso, Jimma University

DOI: $10.7176 / \mathrm{JMPB} / 69-05$

Publication date:March $31^{\text {st }} 2021$

\section{INTRODUCTION}

Most women have uneventful pregnancies and childbirth. Complications and problems can happen quickly and unexpectedly during pregnancy, birth or in the postpartum period. These are severe bleeding, severe headache, blurred vision, convulsions, swollen hands/face, high fever, loss of consciousness, d ifficulty of breathing, severe weakness, severe abdominal pain, accelerated /reduced fetal movement, water breaks without labor, labor lasting $>12 \mathrm{hrs}$, placenta not delivered $30 \mathrm{~min}$ after baby and malodorous vaginal discharge. These leads to complication during pregnancy, labor and delivery and postpartum $[1,2]$.

Hemorrhage, hypertensive disorders, and sepsis are responsible for more than half of maternal deaths worldwide [3]. Most of maternal death occurred because of direct obstetric causes in postpartum period. Hemorrhage is the leading cause of maternal death causing more than half deaths, and pregnancy induced hypertension and anemia are the other major causes of maternal death [4].

These problems are tackled through planning in advance for what to do in an emergency to save time and lives. Through awareness creation among community about danger signs and what to do when they occur the problems can be managed. This can be by organizing finance, developing a plan and an important source of support [5].

Birth Preparedness and Complication Readiness (BPCR) is an essential element of the antenatal care package. It includes the desired place of birth, the preferred birth attendant, funds for any expenses and supplies 
and materials necessary to bring to the facility, transportation to a facility for birth or in the case of a complication, and identification of compatible blood donors in case of complications [6].

BPCR needs the participation of both couple in planning which enables mothers to give birth in the presence of a skilled attendant and this effect is magnified when is carried out by the couple. This indicates that male participation can increase the BPCR practices and so should not focus on women only, as involving the couple is most likely lead to positive care-seeking practices [7].

An estimated global total of 10.7 million women have died in the past 25 years between 1990 and 2015 due to maternal causes [8]. It is also evidenced that 830 women die every day from preventable causes related to pregnancy and childbirth. Almost all maternal deaths (99\%) occur in developing countries more than half occur in sub-Saharan Africa. Maternal mortality between 1990 and 2015 shows that 12 deaths per 100,000 livebirths for high-income regions, but 546 for sub-Saharan Africa. This indicates that there is high variation between high income countries and sub Saharan countries [9]. In Ethiopia report from EDHS, 2016 indicate that still the maternal mortality ratio related to pregnancy is high, 412 per 100,000 live births [10]. Sub Saharan region has maternal deaths that occur at high rates in all three risky periods [11]. By 2030 Sustainable Development Goal 3 target to reduce the global maternal mortality ratio to less than 70 per 100,000 live births [12].

But the death is mainly caused by direct causes that are due to pregnancy and its complication. Study from Eastern Ethiopia showed that only less than half of pregnant women were prepared for birth [13]. Most common causes of maternal mortality are obstructed labor, hemorrhage and hypertension related complication [14]. Men reported that issues related to pregnancy and childbirth are the domain of women according to study done in Uganda. But women were interested in receiving more support from their husbands [15]. Around half women are not prepared from findings of study from Mizan Tepi, even though $77.6 \%$ have information about birth preparedness and complication. This indicates that even though $77.6 \%$ of them know preparedness only half were prepared [16].

Husbands control over household and large purchase decision making affects the preparation of women for delivery. Women's decision making on core household and personal issues are very low [17]. Their involvement in making independent decisions on large purchase is almost none $(0.1 \%)$ [18]. Therefore, the aim of this study was to assess knowledge of husbands about obstetric danger signs and their participation in birth preparedness and complication readiness among husbands in Wara Jarso District.

\section{METHODOLOGY AND MATERIALS}

The study was conducted in Wara Jarso Wereda/district, North Shewa, Oromia regional state that is located at $186 \mathrm{~km}$ to the north of Addis Ababa. According to District health office data the Wereda has $31 \mathrm{kebeles} / \mathrm{villages}$ of which 6 are urban and 25 are rural. And its climatic conditions are dega 7.13\%, woyna dega 43.73\% and kola $49.5 \%$. The Wereda had 40944 households with total population of 191237 . Among these population 95535 were females while 95702 were males. The number of female in reproductive age group was 6820 . The data also indicated that institutional delivery of the Wereda during the past year was $24 \%$. The Wereda had 57 health extension workers, $7 \mathrm{HC}$ and $25 \mathrm{HP}$ during study period with health service coverage of $92 \%$, ANC follow up $65 \%$, institutional delivery $24 \%$ and PNC 24\%. The data indicated that ANC utilization is high but with low institutional delivery. The study was conducted from April 8-28/2019 using community based cross-sectional study design.

The source of population was all men whose wives were pregnant or had given birth within the past one year from study period. All sampled men were included in the study and data were collected at an individual level. Husbands whose wives were third trimester pregnancy during study or had given birth within the past one year from study period was included while husbands who were critically ill and unable to respond to the interview during data collection period excluded from the interview.

The sample size required for the study was calculated based on a single population proportions statistical formula. The sample size for study was 593 after using 1.5-design effect. Wara Jarso District has 31 villages. Among them 10 were selected using rule of thumb, which is $30 \%$. After data of husbands with third trimester pregnant women or husbands whose wives were given birth within the past one year. Totally within these ten villages there were 891 husbands whose wives were pregnant (528) or given birth within the past one year (368). Having their number then for each village the samples were allocated proportionally. Then the study participants were identified by taking their lists using simple random sampling (SRS). After the participants were identified, the data collectors used their list and the data was collected. Selected study participants who were not available during data collection was interviewed the next day.

\section{Operational definition:}

Knowledge of danger sign: Knowledgeable: if husbands knew obstetric danger signs more than mean average score during any of the three phases (pregnancy, childbirth, or post-partum period). Not knowledgeable: if husbands knew obstetric danger signs less than mean average score during the three phases [19, 22]. 
Birth preparedness and complication readiness: Level of birth preparedness and complication readiness was categorized as: prepared: for respondents responded yes for 3 or more of the birth preparedness and complication readiness components. Not prepared for respondents responded yes to less than three of the components of birth preparedness and complication [20,24].

Vaginal bleeding: any vaginal bleeding irrespective of the amount during pregnancy or severe vaginal bleeding or not the same as previous deliveries during labor and delivery [21].

\section{Data Collection Method and Instruments}

The data were collected by face-to-face interviewer administered semi structured questionnaire. The questionnaire was composed of 3 components. These were sociodemographic and socio economic characteristics with 12 items. Among these items the average income was removed from analysis because of missing values $(64.5 \%)$, questions related with obstetric characteristics with 13 items, questions on knowledge of obstetric danger signs, and BPCR. The knowledge of danger sign had components at each 3 stage. The possible danger signs during pregnancy were: vaginal bleeding, severe headache, blurred vision, convulsions, swollen hands/face, high fever, loss of consciousness, difficulty of breathing, severe abdominal pain, severe weakness, reduced fetal movement and water breaks without labour. Possible danger signs during labour were: severe bleeding, severe headache, convulsion, high fever, loss of consciousness, labour lasting greater than $12 \mathrm{hrs}$, and placenta not delivered 30min after baby. Possible danger signs during post-partum period were: severe bleeding, severe headache, convulsion, blurred vision, swollen hand/face, high fever, malodorous vaginal discharge, loss of consciousness, difficulty of breathing, and severe weakness during postpartum. The participants were asked to mention any dangers signs that can occur during the three periods. Questions on birth preparedness and complication readiness includes 6 components such as: saved money for delivery, identified blood donor, identified skilled birth attendant, identified health facility, saved money for emergency, and identified transportation. The tool was adapted from Johns Hopkins Program for International Education in Gynecology and Obstetrics (JHPIEGO) [2]. It was prepared in English. Language experts translated the English version questionnaire into 'Afaan Oromoo' then back to English. Then the data collection was run accordingly. The data was collected using 5 diploma Nurses after one-day training on the objective of the study and tools. Two supervisors supervised data collection.

\section{Data analysis and Processing}

After data collection, the data was checked for completeness before entry to computer. Then the collected data was entered to computer using software, Epidata 3.1 and then exported to SPSS version 23. Husband's knowledge was computed using above average mean score at each phase. After the mean was computed then using this mean the it was as knowledgeable for those who score above average mean score, and not knowledgeable for those who score below average mean score knowledge items. Level of BPCR was categorized as prepared for respondents responded yes to 3 or more of BPCR components, otherwise it was coded as not prepared. Bivariate logistic regression was conducted to explore association of each variable with outcome variables to check which variables had association with the dependent variable individually and multivariate logistic regression (stepwise backward likelihood ratio method) was conducted to analyze factors that were associated with husbands' knowledge of danger signs, and birth plans and complication readiness. All associated variables with the main outcome variables by having odds ratio that reach statistical significance in the bi-variate model $<0.05$ was candidate for the multivariate model at $95 \%$ C.I ( $p$-value $<0.05)$. The data was summarized and the adjusted odds ratios (AORs) estimated; and their corresponding $95 \%$ confidence intervals $(95 \% \mathrm{CI})$ was computed. The result was presented using tables, figures and narratives.

\section{RESULT}

The data were collected from 593 participants, and 574 were completed the interview giving the response rate of 96.8\%. The 19 questionnaires were incomplete and excluded from the analysis. The result was presented as descriptive and table for each components.

\section{Sociodemographic and Socio Economic Characteristics}

The mean age of respondents was $36.5 \pm 7.8$ years. Among the study participants $246(42.9 \%)$ were none educated while only $70(12.2 \%)$ were attended college and above. Regarding the ethnicity of the respondents, 563(98.1\%) were Oromo, and concerning religion 539(93.9\%) were orthodox. Regarding occupation, 390(67.9\%) were farmers and 94(16.4\%) were merchants. Most of them were from rural 484(84.3\%) while 90(15.7\%) were living in urban. Regarding husbands' involvement in health developmental army, 368(64.1\%) of them were not participated (Table 1). 


\section{Obstetrics Characteristics of the Respondents}

The obstetric characteristic of the respondents was identified based on their wives' condition by asking the husbands. Among the respondents' wives of 327(57.0\%) were breastfeeding during data collection. Regarding number of pregnancy wives of 544(94.8\%) respondents were being pregnant more than once and $252(43.9 \%)$ husbands were escorted their wife to health institution in their recent pregnancy. Concerning cultural acceptance of buying clothes and materials for baby before delivery only $107(18.6 \%)$ were responded as it was accepted. Regarding place of delivery of their wives 349(64.2\%) were delivered their last recent pregnancy at home, and $122(21.3 \%)$ were developed obstetric complication. As to number of children 199(36.6\%) of respondents were in the category of 0 to 2 children while $170(31.3 \%)$ were in the category of 3 to 4 children. About $284(49.5 \%)$ of the respondents were heard information of obstetrics danger sings and birth preparedness and complication readiness, and 106(37.3\%) were heard from health professionals. 403(70.2\%) of the respondents mentioned that there was no health facility in their kebele, and 168(29.3\%) need to walk distances of 90 minutes and above. Among the respondents 404(70.4\%) were responded that ambulance were used as transportation in their community (Table 2).

\section{Knowledge of Obstetrics Danger Signs}

During each period, the respondents were asked to mention danger signs they knew. And severe vaginal bleeding was mentioned by $193(33.6 \%)$ during pregnancy, 294(51.2\%) during delivery and $195(34.0 \%)$ during postpartum. Severe headache was mentioned by 160(27.9\%) during pregnancy, 151(26.3\%) during delivery and $186(32.4 \%)$ during postnatal. During pregnancy most of them, 255(44.4\%) and 242(42.2\%) mentioned problems with fetal movement and severe abdominal pain respectively. More than half 335(58.4\%) were mentioned prolonged labour as obstetric danger sign during delivery. Among the respondents 201(35.0\%) and 188(32.8\%) were mentioned severe weakness and swollen hands/faces as danger signs during postpartum period respectively. Problems with fatal movement and water breaks without labour were mentioned as obstetric danger sign by $255(44.4 \%)$ and $200(34.8 \%)$ during pregnancy, while prolonged labour 335(58.4\%) and not delivering placenta $136(23.7 \%)$ were mentioned during delivery. The respondents also mentioned swollen hands $188(32.8 \%)$, fever $176(30.7 \%)$ and severe weakness 201(35.0\%) during post-partum (Table 3).

Knowledge of obstetric danger signs were measured at three periods. There were components used to measure at each period. The knowledge of obstetric danger sign of the respondents were computed at each period using average mean score and categorized as knowledgeable or not for each. The knowledgeable respondents about obstetric danger signs during pregnancy, delivery and postpartum period was $178(31.0 \%)$, $186(32.4 \%)$ and $170(29.6 \%)$ respectively. Then for the three again average mean score was computed to categorize the overall knowledge of respondents. After computing average mean score the overall knowledge of respondents was $184(32.06 \%)$ which was categorized as knowledgeable about obstetric danger signs for those above average mean score or not for less than average mean score.

\section{Birth Preparedness and Complication Readiness}

The respondents were asked to mention the steps they have made during the current pregnancy if their wives were pregnant during study or during the last recent delivery if their wives were given birth within the past one year. Birth preparedness and complication readiness components that were prepared by the respondents were saving money 344(59.9\%), identified skilled birth attendant 61(10.6\%), identified health facility $141(24.6 \%)$ and identified transportation 132(23.0\%). Only 51(8.9\%) were identified the blood donor while only 93(16.2\%) were saved money for emergency cases (Table 4). Level of birth preparedness and complication readiness was categorized as prepared or not prepared. And those who prepared three of BPCR item was categorized as prepared while those less than three were not prepared. Among the respondents $128(22.30 \%)$ were prepared while the rest were not.

\section{Factors Associated with husbands' level of BPCR}

\section{Factors Associated with level BPCR in Bivariate Logistic Analysis}

In Bivariate logistic analysis: age of husband, age of wife, educational status of husband, educational status of wife, occupation of husband, occupation of wife, place of residence, number of pregnancy, escort wife to health facility, cultural acceptability of buying materials for unborn baby, obstetric complication on the last recent pregnancy, source of information, presence of health facility, number of children, mode of transportation in community and time it take to health facility were found to be significantly associated at ( $p$-value $\leq 0.05$ ) with level of BPCR.

Husbands in age category of 45 and above (COR $=.177(95 \% \mathrm{CI} .085, .370), \mathrm{p}=.001)$, having wives in age category of $30-34(\mathrm{COR}=2.494(95 \% \mathrm{CI} 1.416,4.393), \mathrm{p}=.002)$, attended college and above (COR $=24.532(95 \% \mathrm{CI} 11.616,51.812), \mathrm{p}=.001)$, husbands having wives attended college and above(COR $=18.306(95 \% \mathrm{CI}$ 8.960, 37.402), $\mathrm{p}=.001)$, employed $(\mathrm{COR}=13.333(95 \% \mathrm{CI}$ 7.393, 24.046), $\mathrm{p}=.001)$, having 
employed wives $(\mathrm{COR}=9.221(95 \% \mathrm{CI} 4.655,18.269), \mathrm{p}=.001)$, living in urban $(\mathrm{COR}=5.125(95 \% \mathrm{CI} 3.182$, $8.255), \mathrm{p}=.001)$, being a leader of health developmental army $(\mathrm{COR}=.481(95 \% \mathrm{CI} .303, .764), \mathrm{p}=.002)$ were significantly associated with husbands' level of BPCR (Table 5)

In bivariate logistic analysis among the variables in obstetric characteristic: husbands with wives being pregnant once $(\mathrm{COR}=6.893(95 \% \mathrm{CI} 3.186,14.913), \mathrm{p}=.001)$, escorted wife to health institution $(\mathrm{COR}$ $=12.156(95 \%$ CI $7.182,20.575), \mathrm{p}=.001)$, acceptance of buying materials and clothes for baby before delivery $(\mathrm{COR}=7.090(95 \% \mathrm{CI} 4.481,11.217), \mathrm{p}=.001)$, having history of obstetric complication $(\mathrm{COR}=3.058(95 \% \mathrm{CI}$ $(95 \% \mathrm{CI} 1.931,4.843)), \mathrm{p}=.001)$, having information of obstetric danger signs complication $(\mathrm{COR}=8.284(95 \% \mathrm{CI}$ $4.957,13.844), \mathrm{p}=.001)$, having children in category of $\geq 5(\mathrm{COR}=.239(95 \% \mathrm{CI} .131, .434), \mathrm{p}=.001)$ having health institution in villages $(\mathrm{COR}=2.338(95 \% \mathrm{CI} 1.554,3.517), \mathrm{p}=.001)$, and living relatively nearby health facility $(\mathrm{COR}=4.613(95 \% \mathrm{CI} 2.598,8.191), \mathrm{p}=.001)$, transportation on foot to health institution (COR $=2.307(95 \%$ CI $1.380,3.857), \mathrm{p}=.001)$, having knowledge of obstetric danger sign (COR $=10.936$ (95\%CI 6.936, $17.243), \mathrm{p}=.001$ ) were more likely prepared in bivariate logistic analysis (Table 6).

\section{Factors Associated with level of BPCR in Multivariable Logistic Analysis}

After controlling confounding factors in multivariable logistic analysis of sociodemographic and obstetric characteristics with husbands' level of preparedness among variables significantly associated in bivariate logistic regression analysis using backward LR the following variables were left in the final model.

The variables were occupation of husband, place of residence, escort to health institution, cultural acceptance of buying materials before delivery and knowledge of obstetric danger signs. Merchant husbands were 2.272 times $(\mathrm{AOR}=2.272(95 \% \mathrm{CI} 1.153,4.478), \mathrm{p}=.018)$ more prepared compared to farmers. Husbands living in urban were 5.550 times $(\mathrm{AOR}=5.550(95 \% \mathrm{CI} 2.211,13.933), \mathrm{p}=.001)$ more likely to be prepared than those living in rural. And also husbands who escort their wives to health institution were 2.217 times $(\mathrm{AOR}=$ $2.217(95 \% \mathrm{CI} 1.095,4.487), \mathrm{p}=.027)$ more likely prepared compared to did not escort. Those husbands who accepts buying material and clothes for baby before delivery were 3.599 times (AOR $=3.599$ (95\%CI 1.995 , 6.490), $\mathrm{p}=.001$ ) more likely to be prepared than those who think that buying materials for un delivered baby was not good. Knowledgeable husbands about obstetric danger sign were 4.957 times (AOR $=4.957$ (95\%CI 2.726, 9.016), $\mathrm{p}=.001$ ) more likely to be prepared compared to not knowledgeable husbands (Table 7).

\section{DISCUSSION}

However, husbands are the decision makers and heads of the households in this community their knowledge of obstetric danger sign was about one third while their preparedness was less than a quarter. There were variables associated with husbands' birth preparedness. Occupation of both husbands and wives, acceptance of buying materials and clothes before delivery and source of information were factors associated with knowledge, while occupation of husband, place of residence, number of pregnancy, acceptance of buying materials and clothes for baby before delivery and knowledge of obstetric danger sign were associated with birth preparedness.

This study shown that husbands preparedness for delivery and complication was low even though around one third have had knowledge of obstetric danger sign. This finding was higher than finding from southern Ethiopia, Tanzania, northwest Ethiopia [20, 21, 24]. This difference could be explained as time gap and the wives' utilization of maternal care may be improved and initiated the husbands for preparation. study in Kenya was conducted on one factory and participants were selected purposefully. Study from north west Ethiopia were self-administered and this could lead to under scoring may be due to omission of questions.

However level of husbands' preparedness was lower compared to findings from Wolaita Sodo southern Ethiopia and Ambo town Ethiopia [22, 23]. The difference could be explained as study conducted in Ambo, Ethiopia was conducted in urban. There may be exposure to information as they were from urban and probability of wives ANC follow up leads to good preparation. And the finding from southern Ethiopia indicated that the data were collected by reading the options for the respondents while in this study data was collected by asking respondents to mention the steps they have made in preparing themselves.

Bivariate logistic analysis indicated that there were variables significantly associated with preparedness of husbands. Among those variables the following were significantly associated in multi variate logistic analysis. With preparation of husbands: occupation of husbands, place of residence, escort wife to health institution, cultural acceptance of buying materials before delivery, and knowledge of obstetric danger signs.

Place of residence were significantly associated with preparation and husbands living in urban were four times more likely to be prepared than those living in rural. This may be due to accessibility to information and health institution as they may contact with different persons. But the study conducted in southern Ethiopia indicated that place of residence was negatively associated with preparedness of husbands [21]. Study from Tanzania shown that place of residence was significantly associated in bivariate logistic analysis, while not in multivariable logistic analyses [20].

Culture has also its effect on husbands' preparation, husbands who think that preparing material for baby 
before delivery as good were three times more likely to be prepared than those who think that buying materials for un delivered baby was not good. Those accepting buying clothes and other materials as good could prepare themselves as they have no bad perception while those with bad perception could not. Those who escorted their wives to health institution were two times more likely to be prepared compared to those who were not. This could be due to the fact that those who escorted have education from health care providers and initiated to for preparation. Knowledge of obstetric danger sign is significantly associated with preparation.

Knowledgeable husbands about obstetric danger sign were three times more likely to be prepared than not knowledgeable. This may be due to their knowledge of the impact of pregnancy related complications. The finding from Tanzania, ambo, Ethiopia and southern Ethiopia indicated that knowledge of obstetric danger sign were significantly associated with husbands' birth preparedness and complication readiness. Husbands with good knowledge were participated than those with poor knowledge [20, 21, 23]. Husbands' awareness of obstetric danger sign made them participate in preparing necessary materials for complication prevention and early management of the complication. But those husbands having poor knowledge were less likely to be prepared for prevention of the complication. Husbands who interacts with others were knowledgeable about obstetric danger signs and prepared for birth and complication.

Strength and limitations of the study

Strength of the study

The study was conducted using standardized tool. The data collection was conducted at community level and husbands were studied. This study presents evaluating it from the husbands' perspective. Data collectors were trained to teach those who did not prepared for delivery and also about the complications.

Limitations of the study

This study was done using a cross-sectional design, which may result in difficulty of providing causal relationship between husbands' knowledge of obstetric danger signs and other variables and husbands BPCR and other variable. And also there could be a problem of recall bias even though reduced to one year, as the husbands were expected to remember events that occurred up to one year before the study and data were collected by asking husbands to mention the obstetric danger sign they know and activity they made without reading the options for them. To minimize his one year was used. Additionally, there could be social desirability bias especially when husbands were asked regarding cares they given. The husbands could respond as they were done without performing the activities.

\title{
Conclusion
}

More than three fourth of husbands in study area were not prepared for delivery and complication. Their level of preparation for delivery and complication was determined by occupation of husbands, escorting wives to health institution, cultural acceptance of buying materials and clothes before delivery of baby, place of residence and husbands knowledge of obstetric danger sign.

The finding of the study indicated knowledge of participants and their level of preparation was low and they were affected by different factors. Husbands were decision makers with low knowledge of obstetric danger signs and birth preparedness and complication readiness. To manage this problem awareness creation among them is needed. Therefore, is better if district health office, media and health extension workers give health education for husbands about obstetric danger sign, and birth preparedness and complication readiness at community level. Needs further qualitative study using focused group discussion including both husbands and wives.

\author{
Declaration \\ A. List of abbreviations \\ ANC Ante Natal Care \\ AOR Adjusted Odd Ratio \\ BPCR Birth Preparedness and Complication Readiness \\ CI Confidence Interval \\ COR Crude Odds Ratio \\ EDHS Ethiopian Demographic Health Survey \\ HC Health Center \\ HP Health Posts \\ MMR Maternal Mortality Ratio \\ PNC Post-natal Care \\ SDG Sustainable Developmental Goal \\ SPSS Statistical Package for Social Science \\ SRS Simple Random Sampling
}




\section{B. Ethics approval and Consent to participate}

The ethical approval letter was obtained from Jimma university, Institutional Review Board by Ref No IHRPGD/466/2019 on the date of 03/04/2019. During data collection all selected study participants were asked their permission and verbal consent was obtained prior to the interview from selected respondents. In addition, confidentiality of information was assured

\section{Consent for publication}

The study does not include images or videos relating to individual. But concerning other collected and used data in this study; while obtaining consent from each participant, information related to publishing the study finding were addressed and participants were agreed on that.

\section{Availability of data and materials}

The datasets and tools used to support the findings of this study are available from the corresponding author upon request.

\section{E. Competing interests}

The authors declare that they have no any financial or non-financial competing interests.

\section{F. Funding}

Funding for this research was gained from Wolkite University to conduct the study.

\section{G. Authors' contributions}

GT: - The principal investigator designed the study, collect, analyses and interprets the data, and also drafted the manuscript.

SB: - Equally participated in conceptualization of the study, design, analyses and interpretation of results as well.

MB: - Participated in conceptualization and design of the study

\section{H. Acknowledgments}

We would like to thank Wereda health office and health extension workers of selected kebeles for their support in giving us data of the kebele. Our thanks also go to district administration office and village leaders, for their cooperation and facilitation during data collection. We would also like to thank study participants for their participation in the study, and data collectors for participating in collecting data for study. Finally, our thanks go to Jimma University Institute of Health Science, School of Nursing and Midwifery.

\section{Authors' information}

GT: - Lecturer- College of Medicine and Health Sciences, Department of Nursing, Wolkite University, Wolkite, Ethiopia.

SB: - Lecturer- Faculty of Health Sciences, School of Nursing and Midwifery, Jimma University, Jimma, Ethiopia.

MB: - Lecturer, IPD Coordinator of JUMC Medical - Surgical Case Team - Faculty of Health Sciences, School of Nursing and Midwifery, Jimma University, Jimma, Ethiopia.

\section{REFERENCES}

1. WHO, World Bank, UNICEF, UNFPA; Integrated Management of Pregnancy and Childbirth: Managing Complications in Pregnancy and Childbirth: A Guide for Midwives and Doctors, World Health Organization, Geneva, Switzerland, 2003.

2. R. C. Del Barco, Monitoring Birth Preparedness and Complication Readiness. Tools and Indicators for Maternal and Newborn Health,JHPIEGO,Baltimore,Md,USA,2004.

3. Say L, Chou D, Gemmill A, Tunçalp Ö, Moller AB, Daniels J, Gülmezoglu AM, Temmerman M, Alkema L. Global causes of maternal death: a WHO systematic analysis. The Lancet Global Health. 2014 Jun 1;2(6):e323-33.

4. Legesse T, Misra Abdulahi AD. Trends and causes of maternal mortality in Jimma University specialized Hospital, southwest ethiopia: a matched case-control study. International journal of women's health. 2017;9:307-13.

5. World Health Organization. Department of Making Pregnancy Safer, World Health Organization. Counselling for maternal and newborn health care: A handbook for building skills. World Health Organization; 2015.

6. World Health Organization. WHO recommendations on health promotion interventions for maternal and newborn health 2015. World Health Organization; 2015.

7. Islam S, Perkins J, Siddique MA, Mazumder T, Haider MR, Rahman MM, Capello C, Hoque DM, Santarelli C, El Arifeen S, Rahman AE. Birth preparedness and complication readiness among women and couples and its association with skilled birth attendance in rural Bangladesh. PloS one. 2018 Jun 7;13(6):e0197693,1-15..

8. Trends in maternal mortality: 1990 to 2015: estimates by WHO, UNICEF, UNFPA, World Bank Group and the United Nations Population Division. Geneva: World Health Organization; 2015. 
9. Alkema L, Chou D, Hogan D, Zhang S, Moller AB, Gemmill A, Fat DM, Boerma T, Temmerman M, Mathers C, Say L. Global, regional, and national levels and trends in maternal mortality between 1990 and 2015, with scenario-based projections to 2030: a systematic analysis by the UN Maternal Mortality Estimation Inter-Agency Group. The Lancet. 2016 Jan 30;387(10017):462-74..

10. Ethiopian Demographic and Health Survey, Central Statistical Agency, Addis Ababa, Ethiopia. 2016

11. Merdad L, Ali MM. Timing of maternal death: Levels, trends, and ecological correlates using sibling data from 34 sub-Saharan African countries. PloS one. 2018 Jan 17;13(1) : e0189416. 5:1-13.

12. World Health Orgainization, Maternal mortality, Fact sheets 16 February 2018.

13. Tilahun T, Sinaga M. Knowledge of obstetric danger signs and birth preparedness practices among pregnant women in rural communities of Eastern Ethiopia. International Journal of Nursing and Midwifery. 2016 Jan 31;8(1):1-1.

14. Berhan Y, Berhan A. Causes of maternal mortality in Ethiopia: a significant decline in abortion related death. Ethiopian journal of health sciences. 2014;24:15-28.

15. Singh D, Lample M, Earnest J. The involvement of men in maternal health care: cross-sectional, pilot case studies from Maligita and Kibibi, Uganda. Reproductive health. 2014 Dec;11(1):68;1-8.

16. Begashaw B, Tesfaye Y, Zelalem E, Ubong U, Kumalo A. Assessment of Birth Preparedness and Complication Readiness among Pregnant Mothers Attending Ante Natal Care Service in Mizan-Tepi University Teaching Hospital, South West Ethiopia. Clinics Mother Child Health. 2017;14(257):2:1-7.

17. Regassa E, Regassa N. Examining the Low Women Autonomy in Household Decision Makings in Sidama Zone, Southern Ethiopia. Journal of Woman's Reproductive Health. 2016 Jul 22;1(3):10.

18. Alemtsehay Mekonnen, Kerebih Asrese. Household Decision Making Status of Women in Dabat District, North West Ethiopia, 2009 Gc. Science Journal of Public Health. Vol. 2, No. 2, 2014, pp. 111-118. doi: 10.11648/j.sjph.20140202.20, 11-8.

19. Sekoni OO, Owoaje ET. Male knowledge of danger signs of obstetric complications in an urban city in south west Nigeria. Annals of Ibadan postgraduate medicine. 2014;12(2):89-95.

20. August F, Pembe AB, Mpembeni R, Axemo P, Darj E. Men's knowledge of obstetric danger signs, birth preparedness and complication readiness in rural Tanzania. PloS one. 2015 May 7;10(5):e0125978.

21. Debiso AT, Gello BM, Malaju MT. Factors Associated with Men's Awareness of Danger Signs of Obstetric Complications and Its Effect on Men's Involvement in Birth Preparedness Practice in Southern Ethiopia, 2014. Advances in Public Health. 2015;2015.

22. Tadesse M, Boltena AT, Asamoah BO. Husbands' participation in birth preparedness and complication readiness and associated factors in Wolaita Sodo town, Southern Ethiopia. African journal of primary health care \& family medicine. 2018;10(1):1-8.

23. Demissie DB, Bulto GA, Terfassa TG. Involvement of male in antenatal care, birth preparedness and complication readinessand associated factors in Ambo town, Ethiopia. J Heal Med Nurs. 2016;27(5):1423.

24. Mersha AG. Male involvement in the maternal health care system: implication towards decreasing the high burden of maternal mortality. BMC Pregnancy and Childbirth; 2018;1-8.

\section{List of tables}

Table 1: Distribution husbands sociodemographic and economic characteristic in Wara Jarso, Ethiopia, April 2019

\begin{tabular}{llrr}
\hline Variable & Characteristics & Frequency & Percent \\
\hline Age of husbands & $\leq 29$ & 136 & 23.7 \\
& $30-34$ & 116 & 20.2 \\
& $35-39$ & 115 & 20.0 \\
& $40-44$ & 90 & 15.7 \\
& $\geq 45$ & 117 & 20.4 \\
\hline Age of wives & $\leq 24$ & 105 & 18.3 \\
& $25-29$ & 144 & 25.1 \\
& $30-34$ & 134 & 23.3 \\
& $\geq 35$ & 191 & 33.3 \\
\hline Ethnicity of husbands & Oromo & 563 & 98.1 \\
& Others* & 11 & 1.9 \\
\hline Religion of husbands & Orthodox & 539 & 93.9 \\
& Protestant & 27 & 4.7 \\
& Others** & 8 & 1.4 \\
\hline
\end{tabular}




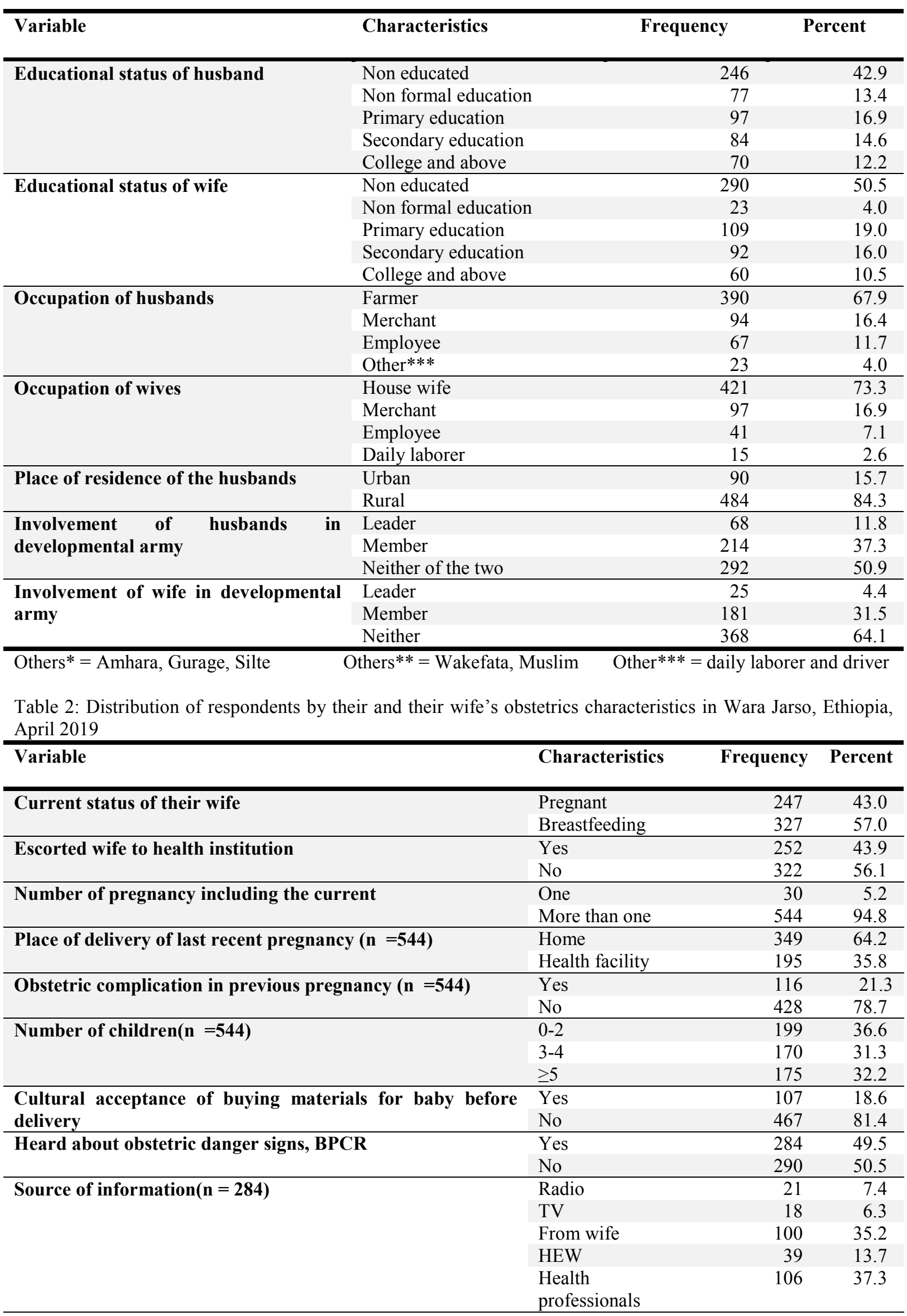




\begin{tabular}{llrr}
\hline Variable & Characteristics & Frequency & Percent \\
\hline Presence of health facility in kebele & & Yes & 171 \\
& No & 403 & 70.2 \\
\hline Time it take from health facility in minutes & $<30$ & 162 & 28.2 \\
& $30-60$ & 163 & 28.4 \\
& $60-90$ & 81 & 14.1 \\
& $>90$ & 168 & 29.3 \\
\hline Mode of transportation to health facility & Ambulance & 404 & 70.4 \\
& Private car & 16 & 2.8 \\
& Cart & 54 & 9.4 \\
\hline Giving birth is women matter and husband has little & Yes foot & 100 & 17.4 \\
\hline contribution & No & 35 & 6.1 \\
\hline
\end{tabular}

Table 3: Knowledge of obstetric danger signs among husbands of Wara Jarso, Ethiopia, April 2019

\begin{tabular}{|c|c|c|}
\hline Variables & Frequency & Percent \\
\hline \multicolumn{3}{|c|}{ During pregnancy } \\
\hline Vaginal bleeding & 193 & 33.6 \\
\hline Severe headache & 160 & 27.9 \\
\hline Blurred vision & 159 & 27.7 \\
\hline Convulsion & 57 & 9.9 \\
\hline Swollen hands or face & 180 & 31.4 \\
\hline High fever & 77 & 13.4 \\
\hline Loss of consciousness & 45 & 7.8 \\
\hline Difficulty of breathing & 65 & 11.3 \\
\hline Severe weakness & 129 & 22.5 \\
\hline Severe abdominal pain & 242 & 42.2 \\
\hline Problems with fetal movement & 255 & 44.4 \\
\hline Water breaks without labour & 200 & 34.8 \\
\hline \multicolumn{3}{|c|}{ Delivery } \\
\hline Severe bleeding & 294 & 51.2 \\
\hline Severe headache & 151 & 26.3 \\
\hline Convulsion & 88 & 15.3 \\
\hline High fever & 131 & 22.8 \\
\hline Loss of consciousness & 90 & 15.7 \\
\hline Labour lasting more than $12 \mathrm{hrs}$ & 335 & 58.4 \\
\hline Placenta not delivered 30 min after baby & 136 & 23.7 \\
\hline \multicolumn{3}{|c|}{ Postpartum } \\
\hline Severe bleeding & 195 & 34.0 \\
\hline Severe headache & 186 & 32.4 \\
\hline Blurred vision & 111 & 19.3 \\
\hline Convulsion & 65 & 11.3 \\
\hline Swollen hands or face & 188 & 32.8 \\
\hline High fever & 176 & 30.7 \\
\hline Malodourous vaginal discharge & 79 & 13.8 \\
\hline Loss of consciousness & 107 & 18.6 \\
\hline Difficulty of breathing & 150 & 26.1 \\
\hline Severe weakness & 201 & 35.0 \\
\hline
\end{tabular}


Table 4: Respondents BPCR among husbands of Wara Jarso, Ethiopia, April 2019

\begin{tabular}{lrr}
\hline \multicolumn{1}{c}{ Variable } & Frequency & Percent \\
\hline Saved money for delivery & 344 & 59.9 \\
Identified blood donor & 51 & 8.9 \\
Identified skilled birth attendant & 61 & 10.6 \\
Identified health facility & 141 & 24.6 \\
Saved money for emergency & 93 & 16.2 \\
Identified transportation & 132 & 23.0 \\
\hline
\end{tabular}

Table 5: Comparison of sociodemographic variable with husbands' level of BPCR in bivariate logistic regression analysis in Wara Jarso, Ethiopia, April 2019

\begin{tabular}{|c|c|c|c|c|c|}
\hline \multirow{2}{*}{\multicolumn{2}{|c|}{ Variable }} & \multicolumn{2}{|c|}{ Prepared } & \multirow[b]{2}{*}{$\mathbf{P}$} & \multirow[b]{2}{*}{ COR 95\%CI } \\
\hline & & \multirow{2}{*}{$\frac{\text { Yes }}{47(34.6 \%)}$} & \multirow{2}{*}{$\frac{\text { No }}{89(65.4 \%)}$} & & \\
\hline Age of husband & $\leq 29$ & & & 1 & 1 \\
\hline & $30-34$ & $31(26.7 \%)$ & $85(73.3 \%)$ & .181 & $.691(.402,1.188)$ \\
\hline & $35-39$ & $25(21.7 \%)$ & $90(78.3 \%)$ & .026 & $.526(.298, .927)$ \\
\hline & $40-44$ & $15(16.7 \%)$ & $75(83.3 \%)$ & .004 & $.379(.196, .731)$ \\
\hline & $\geq 45$ & $10(8.5 \%)$ & $107(91.5 \%)$ & .001 & $.177(.085, .370)$ \\
\hline \multirow[t]{4}{*}{ Age of wife } & $\leq 29$ & $39(37.1 \%)$ & $66(62.9 \%)$ & .001 & $4.112(2.296,7.365)$ \\
\hline & $30-34$ & $38(26.4 \%)$ & $106(73.6 \%)$ & .002 & $2.494(1.416,4.393)$ \\
\hline & $35-39$ & $27(20.1 \%)$ & $107(79.9 \%)$ & .066 & $1.756(.963,3.203)$ \\
\hline & $40-44$ & $24(12.6 \%)$ & $167(87.4 \%)$ & 1 & 1 \\
\hline \multirow{5}{*}{$\begin{array}{l}\text { Educational } \\
\text { of husbands }\end{array}$} & Non educated & $12(4.9 \%)$ & $234(95.1 \%)$ & 1 & 1 \\
\hline & Non formal & $8(10.4 \%)$ & $69(89.6 \%)$ & .087 & $2.261(.888,5.753)$ \\
\hline & Primary & $34(35.1 \%)$ & $63(64.9 \%)$ & .001 & $10.524(5.151,21.502)$ \\
\hline & Secondary & $35(41.7 \%)$ & $49(58.3 \%)$ & .001 & $13.929(6.750,28.740)$ \\
\hline & College+ & $39(55.7 \%)$ & $31(44.3 \%)$ & .001 & $24.532(11.616,51.812)$ \\
\hline \multirow{5}{*}{$\begin{array}{l}\text { Educational } \\
\text { of wife }\end{array}$} & Non educated & $16(5.5 \%)$ & $274(94.5 \%)$ & 1 & 1 \\
\hline & Non formal & $2(8.7 \%)$ & $21(91.3 \%)$ & .532 & $1.631(.351,7.574)$ \\
\hline & Primary & $36(33.0 \%)$ & $73(67.0 \%)$ & .001 & $8.445(4.440,16.064)$ \\
\hline & Secondary & $43(46.7 \%)$ & $49(53.3 \%)$ & .001 & $15.028(7.849,28.772)$ \\
\hline & College + & $31(51.7 \%)$ & $29(48.3 \%)$ & .001 & $18.306(8.960,37.402)$ \\
\hline \multirow{4}{*}{$\begin{array}{l}\text { Occupation } \\
\text { husband }\end{array}$} & Farmer & $39(10.0 \%)$ & $351,90.0 \%)$ & 1 & 1 \\
\hline & Merchant & $43(45.7 \%)$ & $51(54.3 \%)$ & .001 & $7.588(4.495,12.809)$ \\
\hline & Employee & $40(59.7 \%)$ & $27(40.3 \%)$ & .001 & $13.333(7.393,24.046)$ \\
\hline & Other & $6(26.1 \%)$ & $17(73.9 \%)$ & .022 & $3.176(1.183,8.529)$ \\
\hline \multirow[t]{4}{*}{ Occupation of wife } & Housewife & $14(5 \%)$ & $360(85.5 \%)$ & 1 & 1 \\
\hline & Merchant & $40(41.2 \%)$ & $57(58.8 \%)$ & .001 & $4.142(2.545,6.739)$ \\
\hline & Employee & $25(61.0 \%)$ & $16(39.0 \%)$ & .001 & $9.221(4.655,18.269)$ \\
\hline & Daily laborer & $2(13.3 \%)$ & $13(86.7 \%)$ & .900 & $.908(.200,4.123)$ \\
\hline \multirow[t]{2}{*}{ Place of residence } & Urban & $46(51.1 \%)$ & $44(48.9 \%)$ & .001 & $5.125(3.182,8.255)$ \\
\hline & Rural & $82(16.9 \%)$ & $402(83.1 \%)$ & 1 & 1 \\
\hline \multirow{3}{*}{$\begin{array}{l}\text { Husband } \\
\text { involvement in DA }\end{array}$} & Leader & $21(30.9 \%)$ & $47(69.1 \%)$ & .417 & $1.270(.713,2.261)$ \\
\hline & Member & $31(14.5 \%)$ & $183(85.5 \%)$ & .002 & $.481(.303, .764)$ \\
\hline & Neither & $76(26.0 \%)$ & $216(74.0 \%)$ & 1 & 1 \\
\hline
\end{tabular}


Table 6: Comparison of obstetric characteristic variable with husbands' level of BPCR in bivariate logistic regression analysis in Wara Jarso, Ethiopia, April 2019

\begin{tabular}{|c|c|c|c|c|c|}
\hline \multirow{2}{*}{\multicolumn{2}{|c|}{ Variable }} & \multicolumn{2}{|c|}{ Prepared } & \multirow[b]{2}{*}{$\mathbf{P}$} & \multirow[b]{2}{*}{ COR 95\%CI } \\
\hline & & \multirow{2}{*}{$\frac{\text { Yes }}{109(43.3 \%)}$} & \multirow{2}{*}{$\frac{\text { No }}{143(56.7 \%)}$} & & \\
\hline Escorted wife to & Yes & & & .001 & $12.156(7.182,20.575)$ \\
\hline health institution & No & $19(5.9 \%)$ & $303(94.1 \%)$ & 1 & 1 \\
\hline \multirow{2}{*}{$\begin{array}{ll}\text { Number } & \text { of } \\
\text { pregnancy }\end{array}$} & One & $19(63.3 \%)$ & $11(36.7 \%)$ & .001 & $6.893(3.186,14.913)$ \\
\hline & $>$ one & $109(20.0 \%)$ & $435(80.0 \%)$ & 1 & 1 \\
\hline \multirow{2}{*}{$\begin{array}{l}\text { Obstetric } \\
\text { complication }\end{array}$} & Yes & $42(36.2 \%)$ & $74(63.8 \%)$ & .001 & $3.058(1.931,4.843)$ \\
\hline & No & $67(15.7 \%)$ & $361(84.3 \%)$ & 1 & 1 \\
\hline \multirow{3}{*}{$\begin{array}{l}\text { Number } \\
\text { children }\end{array}$} & $0-2$ & $59(29.6 \%)$ & $140(70.4 \%)$ & 1 & 1 \\
\hline & $3-4$ & $34(20.0 \%)$ & $136(80.0 \%)$ & .034 & $.593(.366, .962)$ \\
\hline & $\geq 5$ & $16(9.1 \%)$ & $159(90.9 \%)$ & .001 & $.239(.131, .434)$ \\
\hline \multirow{2}{*}{$\begin{array}{l}\text { Acceptance of } \\
\text { buying materials }\end{array}$} & Yes & $59(55.1 \%)$ & $48(44.9 \%)$ & .001 & $7.090(4.481,11.217)$ \\
\hline & No & $69(14.8 \%)$ & $398(85.2 \%)$ & 1 & 1 \\
\hline \multirow{2}{*}{$\begin{array}{l}\text { Heard } \\
\text { information }\end{array}$} & Yes & $108(38.0 \%)$ & $176(62.0 \%)$ & .001 & $8.284(4.957,13.844)$ \\
\hline & No & $20(6.9 \%)$ & $270(93.1 \%)$ & 1 & 1 \\
\hline \multirow{2}{*}{$\begin{array}{l}\text { Presence of } \mathrm{HI} \text { in } \\
\text { kebele }\end{array}$} & Yes & $57(33.3 \%)$ & $114(66.7 \%)$ & .001 & $2.338(1.554,3.517)$ \\
\hline & No & $71(17.6 \%)$ & $332(82.4 \%)$ & 1 & 1 \\
\hline \multirow{4}{*}{$\begin{array}{ll}\text { Mode } & \text { of } \\
\text { transportation } & \text { to } \\
\text { health facility } & \end{array}$} & Ambulance & $73(18.1 \%)$ & $331(81.9 \%)$ & 1 & 1 \\
\hline & Private car & $7(43.8 \%)$ & $9(56.3 \%)$ & .015 & $3.527(1.272,9.777)$ \\
\hline & Cart & $18(33.3 \%)$ & $36(66.7 \%)$ & .010 & $2.267(1.220,4.214)$ \\
\hline & On foot & $30(30.0 \%)$ & $70(70 \%)$ & .009 & $1.943(1.182,3.195)$ \\
\hline \multirow{4}{*}{$\begin{array}{l}\text { Time it takes } \\
\text { from health } \\
\text { facility to home }\end{array}$} & $<30$ & $60(37.0 \%)$ & $102(63.0 \%)$ & .001 & $4.613(2.598,8.191)$ \\
\hline & $30-60$ & $35(21.5 \%)$ & $128(78.5 \%)$ & .014 & $2.144(1.169,3.932)$ \\
\hline & $60-90$ & $14(17.3 \%)$ & $67(82.7 \%)$ & .196 & $1.639(.775,3.463)$ \\
\hline & $>90$ & $19(11.3 \%)$ & $149(88.7 \%)$ & 1 & 1 \\
\hline \multirow{2}{*}{$\begin{array}{l}\text { Knowledge } \\
\text { danger sign }\end{array}$} & Yes & $94(51.1 \%)$ & $90(48.9 \%)$ & .001 & $10.936(6.936,17.243)$ \\
\hline & No & $34(8.7 \%)$ & $356(91.3 \%)$ & 1 & 1 \\
\hline
\end{tabular}

Table 7: Comparison of sociodemographic and obstetric characteristic variables with husbands' level of BPCR in multivariable logistic regression analysis in Wara Jarso, Ethiopia, April 2019

\begin{tabular}{|c|c|c|c|c|c|c|}
\hline & & \multicolumn{2}{|c|}{ Prepared } & \multirow[b]{2}{*}{ COR 95\%CI } & \multirow{2}{*}{ AOR 95\%CI } & \multirow[b]{2}{*}{$\mathbf{P}$} \\
\hline \multicolumn{2}{|c|}{ Variable } & Yes & No & & & \\
\hline \multirow{4}{*}{$\begin{array}{l}\text { Occupation of } \\
\text { husband }\end{array}$} & Farmer & $39(10.0 \%)$ & $351,90.0 \%)$ & 1 & & \\
\hline & Merchant & $43(45.7 \%)$ & $51(54.3 \%)$ & $7.588(4.495,12.809)$ & $2.272(1.153,4.478)$ & .018 \\
\hline & Employee & $40(59.7 \%)$ & $27(40.3 \%)$ & $13.333(7.393,24.046)$ & $2.220(1.015,4.854)$ & .001 \\
\hline & Other & $6(26.1 \%)$ & $17(73.9 \%)$ & $3.176(1.183,8.529)$ & $.930(.234,3.706)$ & \\
\hline \multirow{2}{*}{$\begin{array}{ll}\text { Place } & \text { of } \\
\text { residence } & \\
\end{array}$} & Urban & $46(51.1 \%)$ & $44(48.9 \%)$ & $5.125(3.182,8.255)$ & $5.550(2.211,13.933)$ & .001 \\
\hline & Rural & $82(16.9 \%)$ & $402(83.1 \%)$ & 1 & & \\
\hline \multirow{2}{*}{$\begin{array}{l}\text { Escorted wife } \\
\text { to HI }\end{array}$} & Yes & $109(43.3 \%)$ & $143(56.7 \%)$ & $12.156(7.182,20.575)$ & $2.217(1.095,4.487)$ & .027 \\
\hline & No & $19(5.9 \%)$ & $303(94.1 \%)$ & 1 & & \\
\hline \multirow{2}{*}{$\begin{array}{l}\text { Buying } \\
\text { materials }\end{array}$} & Yes & $59(55.1 \%)$ & $48(44.9 \%)$ & $7.090(4.481,11.217)$ & $3.599(1.995,6.490)$ & .001 \\
\hline & No & $69(14.8 \%)$ & $398(85.2 \%)$ & 1 & & \\
\hline \multirow{2}{*}{$\begin{array}{ll}\text { Knowledge } & \text { of } \\
\text { danger sign } & \\
\end{array}$} & Yes & $94(51.1 \%)$ & $90(48.9 \%)$ & $10.936(6.936,17.243)$ & $4.957(2.726,9.016)$ & .001 \\
\hline & No & $34(8.7 \%)$ & $356(91.3 \%)$ & 1 & & \\
\hline
\end{tabular}

